\title{
EARLY STAGE DETECTION OF CARDIOMEGALY: AN EXTENSIVE REVIEW
}

\author{
Bhanu Prakash Doppala ${ }^{1}$, Divya Midhunchakkaravarthy ${ }^{1}$ \\ and Debnath Bhattacharyya ${ }^{2}$ \\ ${ }^{1}$ Department of Computer Science and Multimedia, \\ Lincoln University College, Malaysia \\ ${ }^{2}$ Department of Computer Science and Engineering, \\ Vignan's Institute of Information Technology, \\ Visakhapatnam-530049, India \\ \{bhanu.doppala,divya\}@lincoln.edu.my, debnathb@gmail.com
}

\begin{abstract}
Problems related to heart is one of the fundamentally developing issue throughout the globe, prompting a large portion of deaths because of heart issues. The weight of cardiovascular sickness can be enhanced via hazard disease and accordingly essential counteractive action is an imperative need for all engineers of well-being arrangement. For every heart based diseases we need to undergo different medical examinations which kills lot of time to detect the exact root cause, rather than going for several diagnosis mechanisms. In this paper we propose that with limited parameters from the diagnosis results we can identify the issue of Cardiomegaly at early stages.
\end{abstract}

Keywords--Heart disease, Prediction, Cardiomegaly, Healthcare, Classification, and Recurrent Fuzzy Neural Network (RFNN)

\section{INTRODUCTION}

An enlarged heart can be caused by various things, including disease, stretch or other heart conditions. Regularly, there is no known reason, and this condition is called idiopathic enlarged cardiomyopathy. Manifestations of an expanded heart can enhance, however regularly, treatment to address the reason for the augmentation is required. The following graph shows the percentage of age groups effected with Enlarged Heart Problem.

Received: January 8, 2019

Reviewed: March 21, 2019

Accepted: April 3, 2019 


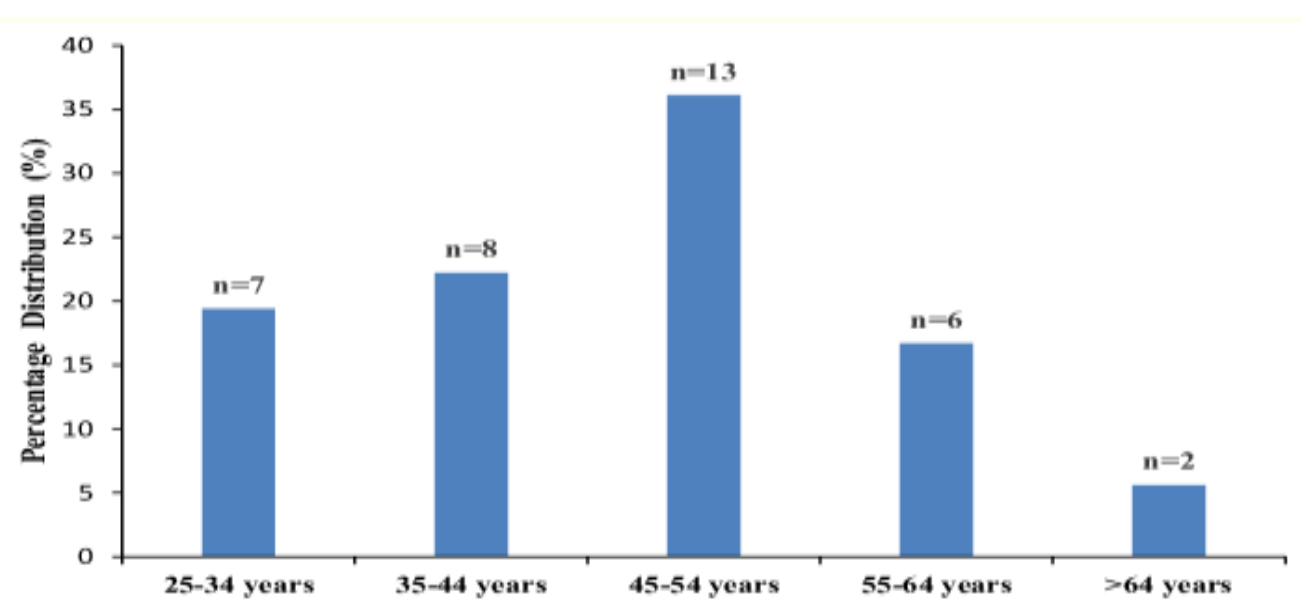

Fig. 1 Affected Age groups with percentage distribution [12]

\section{SYMPTOMS:}

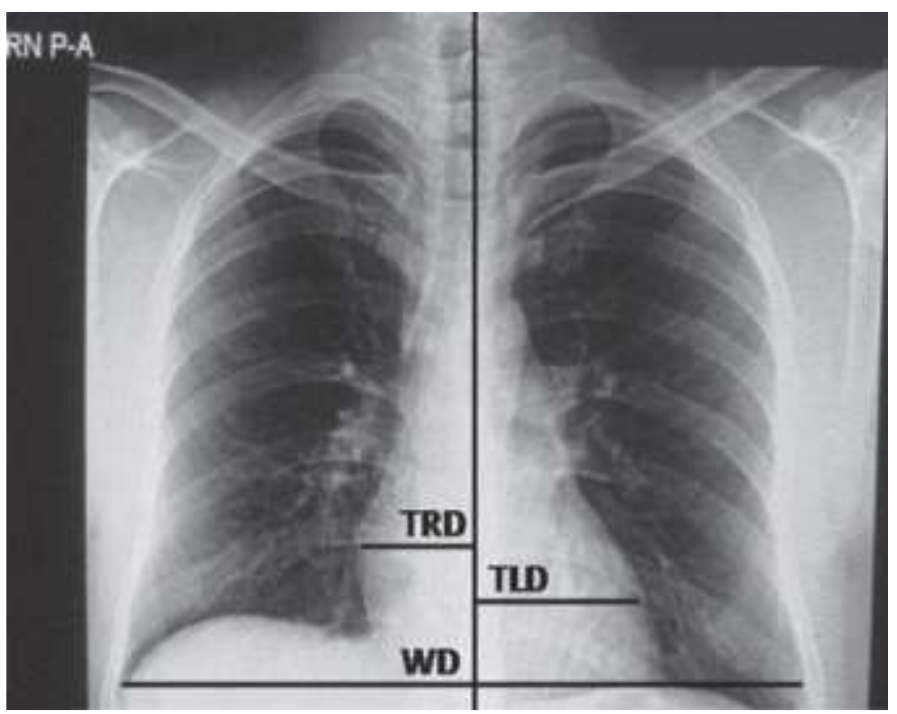

Fig. 2 Heart Size Determination on the Standard PA CXR [2]

Broadened heart indications may not be available or go unnoticed at first as the condition gradually advances. That is the reason why standard registration is imperative to recognize a broadened heart. See your doctor in the event that you have any side effects that can incorporate

- Shortness of breath or a rough voice may happen when physically dynamic or lying level

- $\quad$ Skipped heart pulsates or palpitations 


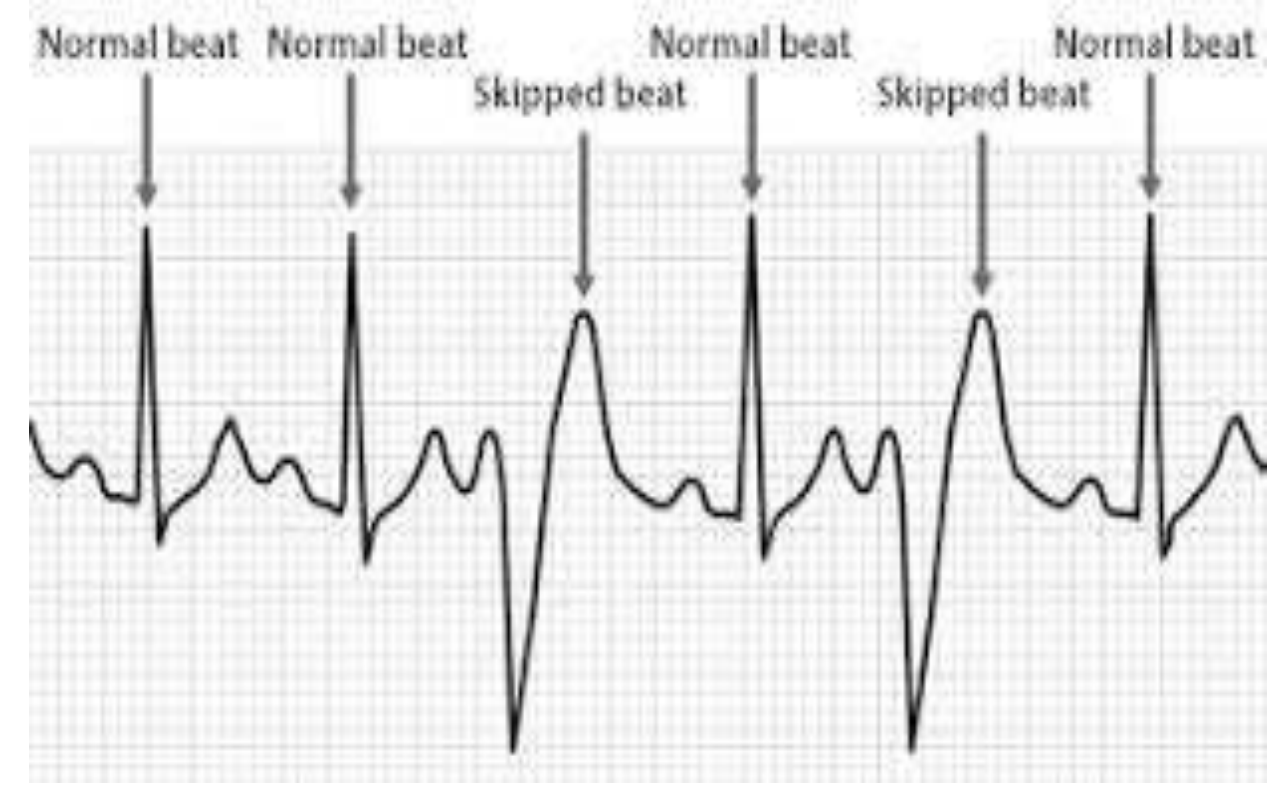

Fig. 3 Skipped Heart Pulses [13]

- $\quad$ Swelling of the leg

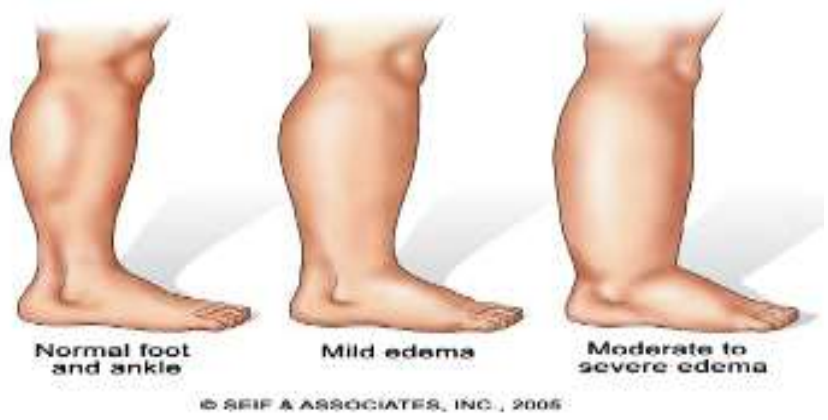

Fig. 4 Swollen legs symptom due to Cardiomegaly [14]

- Fatigue

- Weight gain around the stomach area In the event that you have the accompanying augmented heart indications, look for crisis treatment quickly in light of the fact that you might encounter a heart assault

- Chest torment

- Fainting or close blacking out spells

- Severe trouble relaxing

\section{DIAGNOSIS}

Your specialist will begin with a physical test and an exchange of your indications. Various diverse tests can check the structure and capacity of your heart. A chest X-beam might be the primary test your specialist does on the grounds that it can indicate whether your heart is extended. Tests like these can help your doctor find the cause of the enlargement: 
- Echocardiogram (ECG or EKG) utilizes sound waves to search for issues with your heart's chambers.

- Electrocardiogram screens the electrical action in your heart. It can analyse a sporadic heart musicality and ischemia.

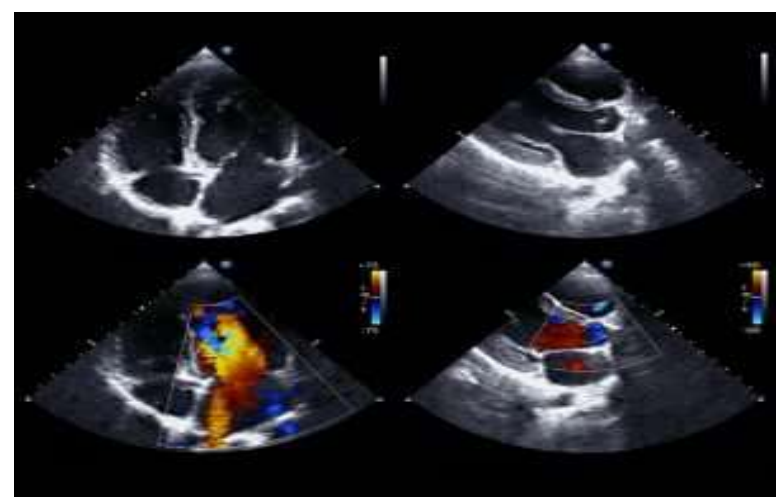

Fig. 5 Abnormality detection using Echocardiogram [15]

- Blood tests check for substances in your blood created by conditions that reason a developed heart, similar to thyroid infection.

- A push test includes walking on a walker machine or speed cycling in gymnasium where heartbeats and breathing will be measured. It can demonstrate how hard your heart is functioning amid exercise.

- Computerized tomography (CT) filters use X-beams to deliver point by point pictures of your heart and different structures in your chest. It can help to analyse valves malady or irritation.

- Magnetic reverberation imaging (MRI) utilizes strong magnets and waves of radio to create images of your heart.

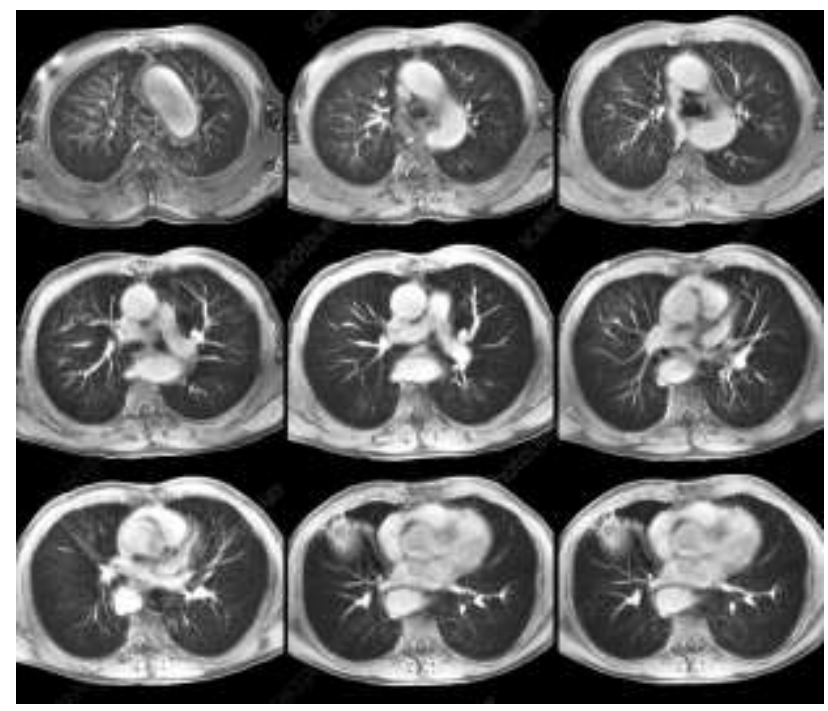

Fig. 6 MRI Image of Healthy Heart [16]

\section{LITERATURE REVIEW}

LathaParthiban and R.Subramanian in the year 2007 proposed their work on prediction of Heart Diseases using CANFIS and Genetic Algorithms [1]. 
U. Sinha et. al., published and identified a change of size in Left Ventricular Enlargement based on Echocardiographic measurements [2].

SnehaNikam, Priyanshi Shukla and Megh Shah have proposed Cardiovascular Disease Prediction Using Genetic Algorithm and Neuro fuzzy System. In this paper, they applied NFS (Neuro Fuzzy System)[3] to the dataset which is nothing but the risk factors, for predicting and training of the network they have proposed back propagation algorithm and for weight optimization they suggested genetic algorithm. The NFS (Neuro Fuzzy System) combines neuro adaptive capability and fuzzy logic reasoning for prediction.

In the year 2017 AnimeshHazra et. al., proposed a review work on Heart Disease Diagnosis and Prediction using Machine learning and Data Mining Techniques [4].

In the year 2013 KiyanaZolfaghar, NarenMeadem, AnkurTeredesai, BrianMuckian and SenjutiBasu Roy, addressed that the heart problems which can be solved through Big Data Solutions in predicting heart diseases to reduce the heart failures.[5]To implement this considering the incidents based on heart failures, several factors from large dataset are identified related to Heart Diseases along with the patients data set from health care systems so that it is possible to create a hybrid dataset.

RuchaShinde, Sandhya Arjun, Priyanka Patil, and Prof.JaishreeWaghmare have used K-Means Clustering and Naive Bayes Algorithms in a process of predicting and identifying Heart Diseases in Intelligent way in the year 2015[6]. Because of busy work schedules and intake of unhygienic food main organ that gets effected in human body would be heart.

In the year 2015 Harmeet S Chana, Clarie A Martin, Holly E Cakebread, Felicia D adjei and Parag $\mathrm{R}$ Gajendragadkar proposed their retrospective study on Diagnostic accuracy of Cardiothoracic ratio on admission chest radiography to detect left or right ventricular systolic dysfunction[7].

In the year 2015 Y. B. Mensah, K. Mensah, S. Asiamah, H. Gbadamosi, E. A. Idun, W. Brakohiapa and A. Oddoye identified a tool for Cardiomegaly screening [8], by establishing the cardiothoracic ratio using check radiographs in an indigenous Ghanian Population.

In the year 2017 Kaan Uyar and Ahmet Ilhan proposed their work on diagnosing heart diseases using Recurrent Fuzzy Neural Networks and Genetic algorithms. One data set related to heart disease used for the survey study where out of more than 300 instances 250 used for training and 50 used for testing purpose [9].

Vincy Cherian and Bindu M.S in the year 2017 proposed an algorithm for Heart Disease Prediction using Naive Bayes Algorithm using Laplace smoothing technique [10]. This method also increases in accuracy when the number of comparative factors decreases and also avoids unnecessary diagnosis which reduces the delay in starting appropriate treatment for the patient.

Leszczynskakatarzyna, Chojnikimaciej, Haponiukireneusz, preis Krzysztof and GerratHaponiokKatarzynain the year 2018 published an article in which they have written about the rare reason of fatal cardiomegaly - prenatal diagnosis of vein of Galen Aneurysmal malfunction [11].

\section{SIGNIFICANCE OF STUDY}

Majority of the heart disappointments emerge due to coronary issues, and hypertension that harms healthy functioning of heart. World Health Organization (WHO) in the year 2K17 evaluated that around 18 million people lost their lives due to heart based diseases which covers $30 \%$ of the overall deaths. It is identified that more than 3 millions of people lost their lives due to coronary diseases (15\% natural deaths) and 6millions of people expired because of heart strokes. Cardiomegaly is an expansion of size of the heart, normally caused by other abnormal conditions, which can be described by chest XRay, or other chest image based Diagnosis. 
Cardiomegaly is a condition where heart valves will be thickened. And when this happens heart faces problem in processing the blood and supplying to different parts. It can happen to any age group person, which is normal for youngsters during Athletic activities and pregnancy woman while deliveries and most of the cases where heart fails in the age group of 30-40years old.

\section{LEFT VENTRICULAR HYPERTROPHY (LVH)}

Another condition which focuses on enlarged heart into the left ventricular hypertrophy $(\mathrm{LVH})$ which thickens the $\mathrm{LVH}$ which happens because exhausting. It is entirely exhorted that individuals should go through heart check-up two times a year to check the conceivable presence of any proof which can cause heart disappointment. Very much prepared well-being associations can direct to many tests which includes Blood tests and Chest X-Ray, where different important parameters helping medical specialists in their findings and their perspectives on the patient's heart disappointment chance and a dimension of deaths because of heart-related ailment among Indians have outperformed on urban Indians, as indicated by an inevitable report in The Lancet. The examination, to be distributed in the August release, likewise recommends that dissimilar to in the West, corpulence may not be a major causes for such deaths in India. The examination, which gives the first-of-its-kind broadly delegate evaluations of cardiovascular mortality in India, demonstrates that heart illnesses generated more than 2 million deaths in India in the year 2015 at different age groups.

\section{SCOPE OF STUDY}

\section{To Identify Cardiomegaly following diagnosis need to be taken}

- Echocardiogram (ECG or EKG) uses sound waves to look for problems in your heart's chambers.

- Electrocardiogram monitors the electrical activity in your heart. It can diagnose an irregular heart rhythm and ischemia.

- Blood tests check for substances in your blood produced by conditions that cause an enlarged heart, like thyroid disease.

\subsection{EXISTING METHODOLOGY 1 USING GENETIC ALGORITHM}

Mostly systems which predict heart based problems uses dataset containing parameters and inputs obtained through complex tests conducted in laboratories. No mechanism identifies heart related problems based on general risk factors like Age, Health history of the family, Diabetes etc. [3]. 


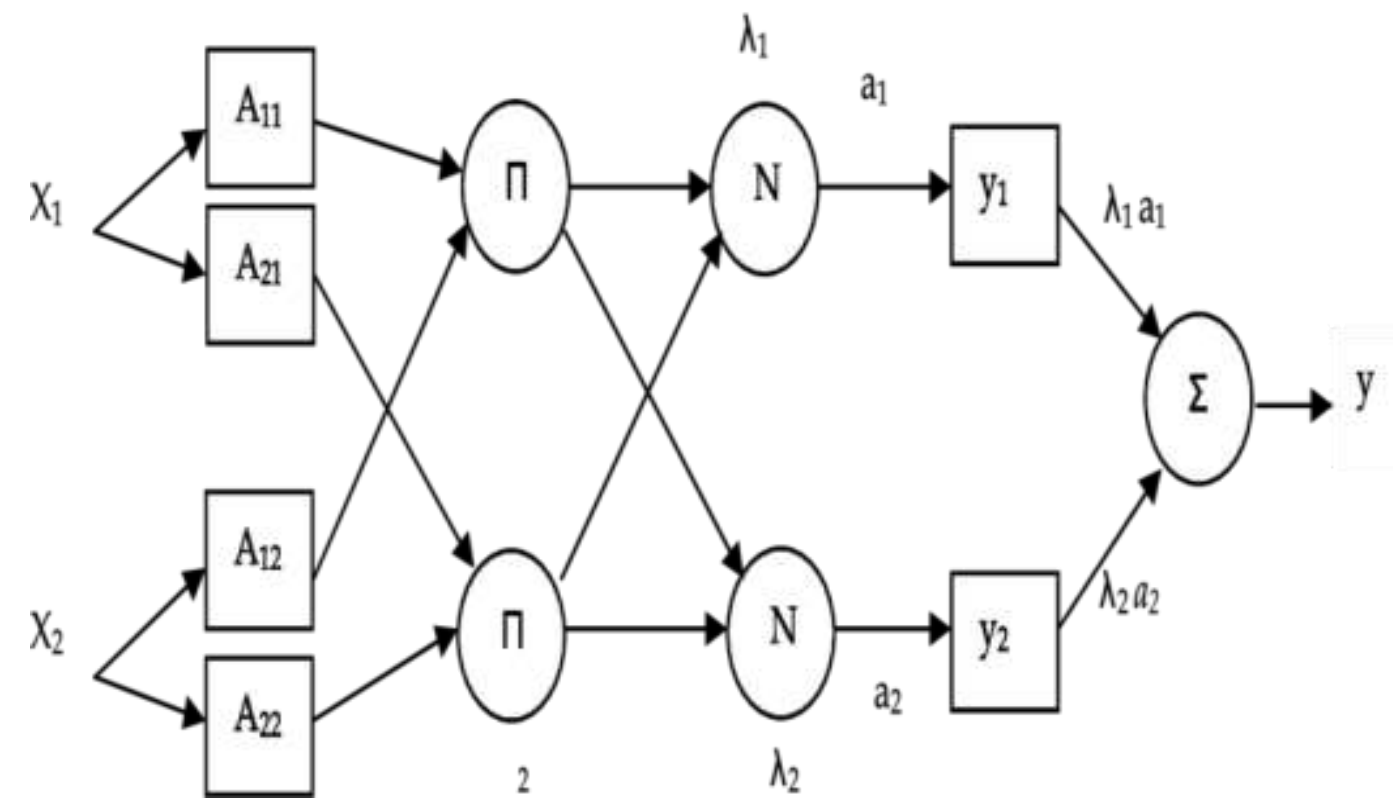

Fig. 8 Architecture of the neuro-fuzzy system- [3]

Layer 1: This is a membership function of fuzzy set related to input, Gaussian membership function is used to identify the parameters [3].

Layer 2: Fixed nodes are used to calculate the firing strength of rule. Product of all the incoming values will be the output at this layer [3].

Layer 3: This layer identifies attributes biggest and smallest values where. Every attributed entropy degree is calculated and identifies the attribute whose entropy value is more than the expected normal value [3].

Layer 4: Multiplies input with normalized firing strength [3].

Layer 5: Overall summation of all the layers will be the generated value of this layer [3].

\subsection{Existing Methodology2 using Recurrent Fuzzy Neural Network (RFNN)}

The Following methodology has more than 10 inputs, more than 5 hidden neurons and with 1 output neuron as shown in Architecture. Coded with 8Bytes long. 


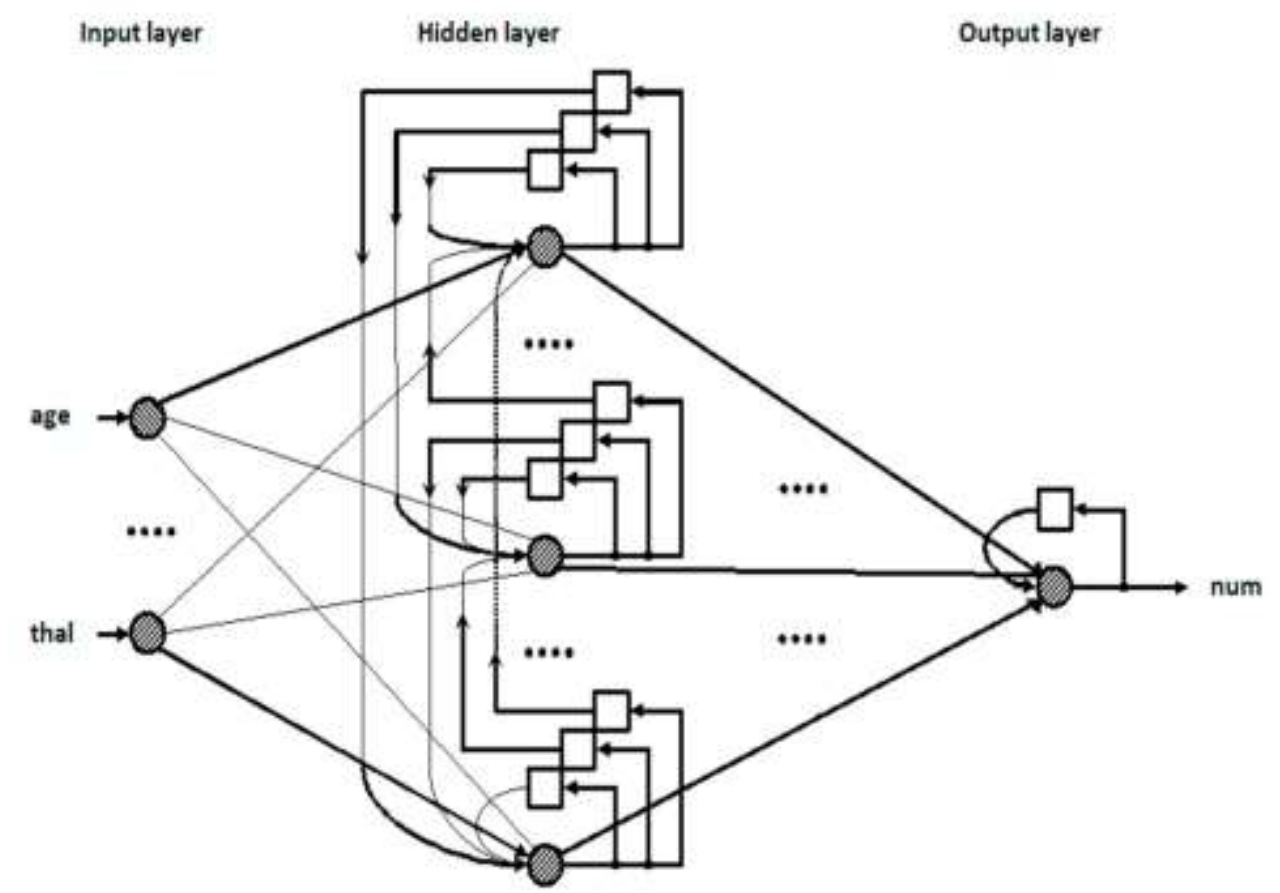

Fig. 7 Recurrent Fuzzy Neural Network (RFNN) Architecture-[9]

This GA based Recurrent Fuzzy Neural Network(RFNN)method working functionality is calculated and identified with Root Mean Square Error (RMSE), Information sensitivity, Information specific, probability of the erroneous calculation and data accuracy of training, test case dataset and the total performance will be analysed through respective example, True Negative (TN) predicting patients with no disease but having chances, False Negative (FN) patients with no disease and no chance of occurrence, the True Positive (TP) which chances for non-heart diseases patients, and the False Positive (FP) is with heart problem and chance of no occurrence.[9]

$\begin{array}{llll}\text { Sensitivity } & = & \mathrm{TP} / \mathrm{TP}+\mathrm{FN} & {[9]} \\ \text { Specificity } & = & \mathrm{TN} / \mathrm{TN}+\mathrm{FP} & {[9]} \\ \text { Precision } & = & \mathrm{P} / \mathrm{TP}+\mathrm{FP} & {[9]} \\ \mathrm{F}-\mathrm{Score} & = & \text { Recall } * \text { Precision } / \text { Recall }+ \text { Precision } & \text { [9] } \\ \mathrm{PME} & = & \mathrm{FP}+\mathrm{FN} / \mathrm{TP}+\mathrm{FP}+\mathrm{TN}+\mathrm{FN} & \text { [9] } \\ \text { Accuracy } & = & \mathrm{TP}+\mathrm{TN} / \mathrm{TP}+\mathrm{FP}+\mathrm{TN}+\mathrm{FN} & \end{array}$

Hence, result evaluation of the diagnosis for heart related diseases using GA based Recurrent Fuzzy Neural Network(RFNN) approach was obtained using a machine with the following configuration where processor is of Intel i7 with Primary memory of 8GB/16GB, Running with Linux Operating System and Java Environment. The testing set (with more than 45 instances) results obtained based on the Recurrent Fuzzy Neural Network(RFNN)approach had a sensitivity value of $100 \%$, a specificity value of $95 \%$, precision value of 96\%, and F-score value of 0.9 and accuracy rate is $98 \%$ [9]. Following approach resulted with a rate of $100 \%$ for the patients with no heart disease were found to have no chance of heart disease in the testing set (20 number of instances). From the 
dataset of total 290 instances results had a sensitivity of $98 \%$, a specificity of $96 \%$, a precision of 95\%, and F-score of 0.9 and accuracy rate is $97 \%$ is obtained [9].

\section{RESULT\& ANALYSIS}

When compared different combination of inputs to Recurrent Fuzzy Neural Network (RFNN) over number of attributes have been be identified towards accurate results in Recurrent Fuzzy Neural Network (RFNN)architecture [9]

I have taken 3 scenarios to review the working mechanism of Recurrent Fuzzy Neural Network architecture proposed with different methods to identify the patients with heart problems.

Table I. Results identified with less number of input samples

\begin{tabular}{|l|c|c|c|c|c|c|c|c|c|}
\hline $\begin{array}{l}\text { Paramete } \\
\text { rs }\end{array}$ & TN & FN & TP & FP & $\begin{array}{l}\text { TOT } \\
\text { AL }\end{array}$ & $\begin{array}{l}\text { SENSITI } \\
\text { VITY }\end{array}$ & $\begin{array}{l}\text { SPECIFI } \\
\text { CITY }\end{array}$ & $\begin{array}{l}\text { PRECISI } \\
\text { ON }\end{array}$ & $\begin{array}{l}\text { ACCUR } \\
\text { ACY }\end{array}$ \\
\hline $\begin{array}{l}\text { Training } \\
\text { set }\end{array}$ & 40 & 2 & 30 & 2 & 74 & 94 & 57 & 94 & 95 \\
\hline $\begin{array}{l}\text { Testing } \\
\text { set }\end{array}$ & 5 & 1 & 2 & 1 & 9 & 66 & 71 & 66 & 77 \\
\hline Overall & 45 & 3 & 32 & 3 & 83 & 91 & $\mathbf{5 8}$ & 91 & 54 \\
\hline
\end{tabular}

Table II. Results identified with moderate number of input samples

\begin{tabular}{|l|c|c|c|c|c|c|c|c|c|}
\hline $\begin{array}{l}\text { Paramete } \\
\text { rs }\end{array}$ & TN & FN & TP & FP & $\begin{array}{l}\text { TOT } \\
\text { AL }\end{array}$ & $\begin{array}{l}\text { SENSITI } \\
\text { VITY }\end{array}$ & $\begin{array}{l}\text { SPECIFI } \\
\text { CITY }\end{array}$ & $\begin{array}{l}\text { PRECISI } \\
\text { ON }\end{array}$ & $\begin{array}{l}\text { ACCUR } \\
\text { ACY }\end{array}$ \\
\hline $\begin{array}{l}\text { Training } \\
\text { set }\end{array}$ & 120 & 5 & 105 & 5 & 235 & 95 & 53 & 95 & 96 \\
\hline $\begin{array}{l}\text { Testing } \\
\text { set }\end{array}$ & 30 & 2 & 12 & 1 & 45 & 86 & 71 & 92 & 93 \\
\hline Overall & 150 & 7 & 117 & 6 & 278 & $\mathbf{9 4}$ & 56 & $\mathbf{9 5}$ & $\mathbf{9 6}$ \\
\hline
\end{tabular}

Table III. Results identified with large number of input samples

\begin{tabular}{|l|c|c|l|l|l|l|l|l|c|}
\hline $\begin{array}{l}\text { Paramete } \\
\text { rs }\end{array}$ & TN & FN & TP & FP & $\begin{array}{l}\text { TOT } \\
\text { AL }\end{array}$ & $\begin{array}{l}\text { SENSITI } \\
\text { VITY }\end{array}$ & $\begin{array}{l}\text { SPECIFI } \\
\text { CITY }\end{array}$ & $\begin{array}{l}\text { PRECISI } \\
\text { ON }\end{array}$ & $\begin{array}{l}\text { ACCUR } \\
\text { ACY }\end{array}$ \\
\hline $\begin{array}{l}\text { Training } \\
\text { set }\end{array}$ & 420 & 35 & 240 & 25 & 720 & 53 & 64 & 91 & 92 \\
\hline $\begin{array}{l}\text { Testing } \\
\text { set }\end{array}$ & 150 & 10 & 48 & 5 & 213 & 83 & 76 & 91 & 93 \\
\hline Overall & 570 & 45 & 420 & 40 & 1075 & 90 & $\mathbf{5 8}$ & 91 & 92 \\
\hline
\end{tabular}


Table IV. Comparison table for Input Sample Values and respective changes in output parameters

\begin{tabular}{|l|c|c|c|}
\hline $\begin{array}{l}\text { Samples vs Percent of } \\
\text { Metrics }\end{array}$ & $\begin{array}{c}\text { LESS NO OF } \\
\text { SAMPLES }\end{array}$ & $\begin{array}{c}\text { MODERATE NO } \\
\text { OF SAMPLES }\end{array}$ & $\begin{array}{c}\text { LARGE NO OF } \\
\text { SAMPLES }\end{array}$ \\
\hline SENSITIVITY & $85-90$ & $\mathbf{9 0}-\mathbf{9 5}$ & $85-90$ \\
\hline SPECIFICITY & $\mathbf{5 5}-\mathbf{6 0}$ & $50-55$ & $\mathbf{5 5}-\mathbf{6 0}$ \\
\hline PRECISION & $85-90$ & $\mathbf{9 0}-\mathbf{9 5}$ & $85-90$ \\
\hline ACCURACY & $50-55$ & $\mathbf{> 9 5}$ & $90-95$ \\
\hline
\end{tabular}

1. Sensitivity component which changes according to the changes in the input producing better results for the minimum input samples and degrading in performance when input samples increases.

2. Specificity value producing better results for both less number of input samples and large number of input samples but slight change in the performance effected with moderate number of input samples.

3. Performance of the Precision value works fine with the moderate data and slight change in the performance with less number of samples and large number of input samples.

4. For moderate input samples Accuracy brings better results and slight change in the performance in the remaining two cases.

\section{CONCLUSION}

Deaths due to heart diseases are rapidly increasing day by day and one of the reasons for such is Cardiomegaly (Increase in the size of heart) for various reasons this is happening to people of all the age groups. Especially for mid aged group daily routines and food habits causing lot of trouble because of busy lives. As to solve this Kaan Uyar and Ahmet Ilhan proposed a solution by taking the parameters that mainly causes the cardiomegaly and detecting them in early stages before it reaches to stroke [9].

Including some of these parameters while making the regular health check-up may definitely help in identifying the Cardiomegaly. Since Recurrent Fuzzy Neural Network(RFNN)method produces better result, we can achieve the best result with the limited parameters by taking less number of heart based tests. To achieve this, we can design a hybrid algorithm which uses RFNN networks methodology to bring better results even with limited number of samples.

\section{REFERENCES}

[1] Kenney, M. \& Zysman, J. (2016). The rise of the platform economy. Issues in Science and Technology, 32(3), 61.

[2] LathaParthiban and R.Subramanian,"Intelligent Heart Disease Prediction System using CANFIS and Genetic Algorithm",World Academy of Science, Engineering and TechnologyInternational Journal of Medical and Health Sciences Vol: 1, No: 5, 2007,PP 1-2.

[3] U.Sinha, U.S.Sahay, S.A.Athavale, R.Deopujari and S.Kumar,"comparative study of cardiac size by chest X-ray and echocardiography",Journal of the Anatomical Society of India 62 (2013),PP 28-32.

[4] SnehaNikam, Priyanshi Shukla and MeghShah,"Cardiovascular Disease Prediction Using Genetic Algorithm and Neuro fuzzy System",International Journal of Latest Trends in Engineering and Technology Vol.(8)Issue(2), PP108-109.

[5] AnimeshHazra, Subrata Kumar Mandal, Amit Gupta, Arkomita Mukherjee and AsmitaMukherjee,"Heart Disease Diagnosis and Prediction Using Machine Learning and Data Mining Techniques:AReview",Advances in Computational Sciences and Technology ISSN 0973-6107 Volume 10, Number 7 (2017), PP 20-23. 
[6] KiyanaZolfaghar, NarenMeadem, AnkurTeredesai, BrianMuckian and SenjutiBasuRoy,"Big Data Solutions for Predicting Risk-of-Readmission for Congestive Heart Failure Patients", 2013 IEEE International Conference on Big Data, PP 65-67.

[7] RuchaShinde, Sandhya Arjun, Priyanka Patil, Prof.JaishreeWaghmare,"An Intelligent Heart Disease Prediction System Using K-Means Clustering and Naive Bayes Algorithm",International Journal of Computer Science and Information Technologies, Vol. 6 (1), 2015,PP 637-638.[7]Harmeet S Chana, Clarie A Martin, Holly E Cakebread, Felicia D adjei and Parag R Gajendragadkar ,"Diagnostic accuracy of cardiothoracic ratio on admission chest radiography to detect left or right ventricular systolic dysfunction: a retrospective study",Journal of the Royal Society of Medicine; 2015, Vol. 108(8),PP 2-4.

[8] Y. B. Mensah, K. Mensah, S. Asiamah, H. Gbadamosi, E. A. Idun, W.Brakohiapa and A. Oddoye,"Establishing The Cardiothoracic Ratio Using Chest Radiographs In An Indigenous Ghanian Population: A Sample Tool For Cardiomegaly Screening”, Ghana Medical Journal Volume 49, Number 3 September 2015, PP 160-162.

[9] Kaan Uyar and Ahmet Ilhan, "Diagnosis of heart disease using genetic algorithm based trained recurrent fuzzy neural networks", ICSCCW, 22-23 August 2017, Budapest, Hungary. PP 590-592

[10] Vincy Cherian and BinduM.S,"Heart Disease Prediction using Naive Bayes Algorithm and Laplace smoothing technique neural networks",9th International Conference on Theory and Application of Soft Computing,", International Journal of Computer Science Trends and Technology (IJCST) - Volume 5 Issue 2, Mar - Apr 2017, PP 68-70.

[11] Leszczynskakatarzyna, Chojnikimaciej, Haponiukireneusz, preis Krzysztof and GerratHaponiokKatarzyna, "The Rare Reason of Fatal Cardiomegaly-Prenatal Diagnosis of Vein of Galen Aneurysmal Malformation”, Biomed J Sci\& Tech Res Volume 5- Issue 5: 2018, PP 1-2.

[12] https://www.researchgate.net/figure/Age-distribution-of-respondents-withcardiomegaly_fig1_272088967 [Last Referred on 11.03.2019]

[13] https://www.healtheuniversity.ca/en/cardiaccollege/Disease/How_The_Heart_Works/Pages/irregularbeats.aspx[Last Referred on 11.03.2019]

[14] https://www.lorisangels.com/single-post/2015/10/15/Tips-for-Dealing-with-Edema-Caused-byCongestive-Heart-Failure-CHF [Last Referred on 11.03.2019]

[15] https://www.impella.com/blog/is-an-echocardiogram-right-for-me/ [Last Referred on 11.03.2019]

[16] https://www.sciencephoto.com/media/317066/view/healthy-heart-mri[Last Referred on 11.03.2019] 
International Journal of Advanced Science and Technology Vol.125 (2019) 